\title{
Cytogenetic Characterization of Induced Sterility in Ornithogalum virens L.
}

\author{
Sitesh C. Biswas ${ }^{1}$ and Amal K. Biswas ${ }^{2, *}$ \\ ${ }^{1}$ Pulses and Oilseeds Section, BRAC, Agric. Res. Centre, Jogitala, BRRI, Joydebpur, \\ Gajipur, Bangladesh \\ ${ }^{2}$ Cytogenetics and Plant Breeding Lab, Department of Botany, University of Kalyani, \\ Kalyani-741235, Nadia, West Bengal, India
}

Received December 19, 2005; accepted February 10, 2006

\begin{abstract}
Summary Cytogenetic investigation was carried out in 2 gamma-ray induced semisterile plants for 2 consecutive years in Ornithogalum virens L. They were characterized as translocation heterozygotes I and II (TH-I and TH-II). Meiotic analysis revealed regular presence of a quadrivalent in the microsporocytes of both the plants at diakinesis and metaphase I. Close association of the quadrivalent with nucleolus was the unique feature in TH-I. This might happen through reciprocal translocation between 2 non-homologous pairs of chromosomes, 1 pair possessing secondary constrictions. Non-adherence of the quadrivalent with nucleolus, on the other hand, rules out involvement of the satellited chromosomes in reciprocal translocation and quadrivalent association in TH-II. Chain shaped quadrivalent was more common in TH-I than ring configuration, while the reverse was true for TH-II, possibly due to variation in the size of the interchanged segments. Longer segments offering better scope of chiasma formation may facilitate origin of a ring of four; but a chain quadrivalent may arise due to shorter size of interchanged segments providing little or no chance of chiasma. Quadrivalent association may be primarily attributed for pollen sterility which enhanced possibly due to high incidence of ring configuration and adjacent orientation in TH-II. Conversely, frequent occurrence of chain quadrivalent and alternate orientation might have restored fertility appreciably in $\mathrm{TH}-$ I. Anaphasic anomalies were identical in both.
\end{abstract}

Key words Ornithogalum virens L, Induced translocation heterozygote, Semisterility, Cytogenetic investigation.

Ornithogalum virens L., a member of the family Liliaceae, is a good material for routine chromosome studies (Jauhar and Storey 1982). Presence of only a few but long-sized chromosomes $(2 n=6)$ with good stainability and advantage of sexual as well as vegetative means of propagation provided this plant species with the potentiality to be exploited for cytogenetic manipulation through induced mutagenesis. Informations in this regard are, however, lacking in the available literatures. An endeavour was made to explore this possibility by analyzing meiotic consequence in the post-irradiated plants of $O$. virens L., and in course of this investigation, it was possible to identify 2 of the treated plants with remarkably reduced fertility. Cytogenetic peculiarities observed in these sterile plants have been depicted precisely in the present text.

\section{Materials and methods}

Fresh dry seeds of Ornithogalum virens L. were irradiated with different doses of gamma-rays ( $10 \mathrm{kr}-1 \mathrm{~h}$ gap $-10 \mathrm{kr}, 15 \mathrm{kr}-1 \mathrm{~h}$ gap- $15 \mathrm{kr}, 20 \mathrm{kr}-1 \mathrm{~h}$ gap-20 kr) from the cobalt source in Central Research Institute of Jute and Allied Fibre, Barrackpore, West Bengal, India. Seedlings raised from

*Corresponding author, e-mail: kalyaniab@rediffmail.com 


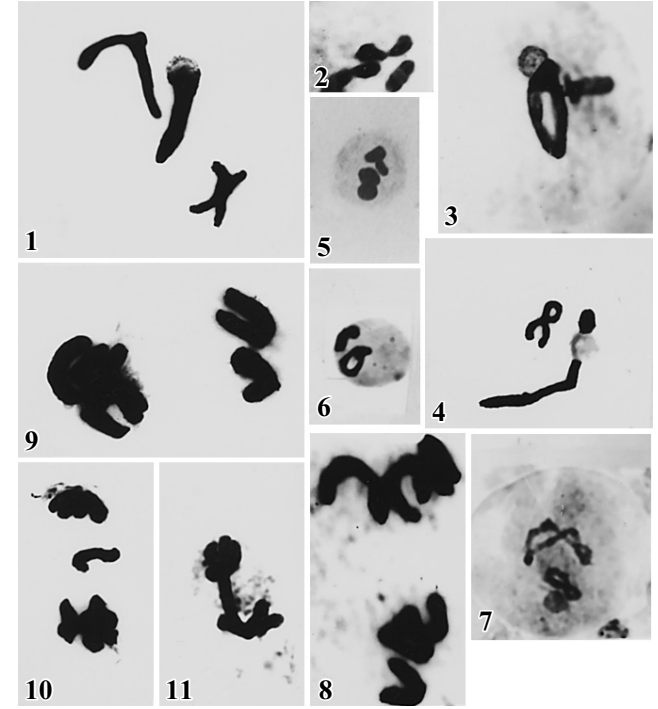

Figs. 1-7. Pairing association of meiotic chromosomes in control and translocation heterozygotes of Ornithogalum virens L. 1) Diakinesis with 3 II in control, one attached to nucleolus and two showing chiasmata. 2) M I with 3 II in control. 3) A ring quadrivalent attached to nucleolus at diakinesis with a bivalent in TH I. 4) Diakinesis showing a chain quadrivalent adhered to nucleolus in TH I with a bivalent. 5) M I showing a quadrivalent with two univalents in TH I. 6) A bivalent closed to nucleolus in TH II with a quadrivalent at diakinesis. 7) A twisted ring quadrivalent showing chiasmata with an 8-shaped bivalent in TH II.

Figs. 8-11. Anaphasic chromosomal behaviour in control and heterozygotes. 8) Equal separation of A I chromosomes in control. 9) Unequal separation in TH I. 10) A I showing a lagging chromosome in TH I. 11) A I with a bridge in TH II.

Figs. 1, 3-4, 8-11: $\times 2100$; Figs. 2, 5-6: $\times 1500$; Fig. 7: $\times 1800$.

Table 1. Meiotic pairing association and chiasma frequency in translocation heterozygotes and control plants of Ornithogalum virens L.

\begin{tabular}{|c|c|c|c|c|c|c|c|c|c|c|}
\hline \multirow{3}{*}{ Plants } & \multirow{3}{*}{ Year } & \multirow{3}{*}{$\begin{array}{l}\text { No. of } \\
\text { PMCs }\end{array}$} & \multicolumn{8}{|c|}{ Occurrence (\%) at diakinesis and metaphase I } \\
\hline & & & \multirow{2}{*}{$\begin{array}{l}\text { Chromosome } \\
\text { association }\end{array}$} & \multirow{2}{*}{$\begin{array}{c}\text { Frequency } \\
(\%)\end{array}$} & \multicolumn{2}{|c|}{ Quadrivalent } & \multicolumn{2}{|c|}{ Orientations } & \multicolumn{2}{|c|}{ Chiasma frequency } \\
\hline & & & & & Ring & Chain & Alternate & Adjacent & /cell & /bivalent \\
\hline \multirow[t]{3}{*}{ TH I } & 1 st yr & 120.00 & $1 \mathrm{IV}+1 \mathrm{II}$ & 100.00 & 21.40 & 78.60 & 52.50 & 47.50 & 6.90 & 2.30 \\
\hline & 2nd yr & 623.00 & $1 \mathrm{IV}+1 \mathrm{II}$ & 99.68 & 5.91 & 94.09 & 57.02 & 42.98 & 6.44 & 2.14 \\
\hline & & & $1 \mathrm{IV}+2 \mathrm{I}$ & 0.32 & & & & & & \\
\hline \multirow[t]{4}{*}{ TH II } & 1 st yr & 358.00 & $1 \mathrm{IV}+1 \mathrm{II}$ & 76.41 & 84.80 & 15.20 & 38.40 & 61.60 & 6.61 & 2.20 \\
\hline & & & 3 II & 23.59 & & & & & & \\
\hline & 2nd yr & 728.00 & $1 \mathrm{IV}+1 \mathrm{II}$ & 97.01 & 94.52 & 5.48 & 45.71 & 52.95 & 5.97 & 1.99 \\
\hline & & & $1 \mathrm{IV}+2 \mathrm{I}$ & 2.98 & & & & & & \\
\hline \multirow[t]{2}{*}{ Control } & 1 st yr & 472.00 & $3 \mathrm{II}$ & 100.00 & & & & & 8.87 & 2.94 \\
\hline & 2nd yr & 534.00 & 3 II & 100.00 & & & & & 8.35 & 2.61 \\
\hline
\end{tabular}

both treated and untreated materials produced bulb-lets in the first year, which matured in to full grown bulbs in the second year. Setting of flower-bud, as usual, could be encountered from this stage. For meiotic studies, suitable-sized flower-buds were collected separately from irradiated as well as control (untreated) plants between 9 am and 10 am and fixed immediately in Carnoy's fluid $(6: 3: 1 \mathrm{v} / \mathrm{v}$ ethyl alcohol, chloroform, and acetic acid). After $24 \mathrm{~h}$ the fixed buds were washed twice with $70 \%$ ethanol and finally preserved in $70 \%$ alcohol at $4^{\circ} \mathrm{C}$. PMCs (pollen mother cells) were studied by smearing the fixed anthers in $1 \%$ aceto-carmine solution. Pollen fertility was determined at random from freshly opened flowers by staining their pollen grains with $1 \%$ aceto-carmine solution both in case of irradiated and control plants. Unstained and deformed pollen grains were treated as sterile. Photomicrographs were taken from suitable preparations. 
Table 2. Anaphasic anomalies and pollen sterility in translocation heterozygotes and control plants of Ornithogalum virens

\begin{tabular}{|c|c|c|c|c|c|c|c|c|}
\hline \multirow{2}{*}{ Plant } & \multirow{2}{*}{ Year } & \multirow{2}{*}{$\begin{array}{l}\text { No. of } \\
\text { PMCs }\end{array}$} & \multicolumn{6}{|c|}{ Frequency $(\%)$ of anaphase I cells with anomalies } \\
\hline & & & $\begin{array}{c}\text { Anaphase } \\
\text { bridge }\end{array}$ & Laggard & $\begin{array}{l}\text { Unequal } \\
\text { separation }\end{array}$ & $\begin{array}{c}\text { Late } \\
\text { separation }\end{array}$ & $\begin{array}{c}\text { Bridge with } \\
\text { a laggard }\end{array}$ & $\begin{array}{l}\text { Pollen } \\
\text { sterility }\end{array}$ \\
\hline \multirow[t]{2}{*}{ TH-I } & 1 st yr & 378.00 & 1.73 & 1.86 & 1.21 & 0.79 & 0.52 & 50.40 \\
\hline & 2nd yr & 317.00 & 2.84 & 2.20 & 0.95 & - & 1.26 & 50.55 \\
\hline \multirow[t]{2}{*}{ TH-II } & 1 st yr & 446.00 & 0.67 & 2.20 & 4.48 & 0.90 & 0.22 & 72.70 \\
\hline & 2nd yr & 917.00 & 0.33 & 2.94 & 2.73 & - & 0.22 & 60.38 \\
\hline \multirow[t]{2}{*}{ Control } & 1 st yr & 568.00 & - & - & - & - & - & 3.90 \\
\hline & 2nd yr & 496.00 & - & - & - & - & - & 1.12 \\
\hline
\end{tabular}

\section{Observations}

The post-irradiated plants in Ornithogalum virens L. were found to be phenotypically indistinguishable barring remarkably lower frequency of fruit-setting than the control plants observed in 2 of the treated materials raised through irradiation with $20 \mathrm{kr}-1 \mathrm{~h}$ gap- $20 \mathrm{kr}$ gamma rays. Meiotic studies carried out for 2 consecutive years revealed that in contrast to usual occurrence of 3 bivalents in the PMCs of control $(2 n=6)$, regular presence of a quadrivalent was encountered in the microsporocytes of the 2 semisterile plants during diakinesis and metaphase I (Figs. 1-6, Table 1). Both the plants manifested the characteristics of translocation heterozygotes; they were, however, found to be different from each other owing to their individual meiotic distinctiveness and identified as TH (translocation heterozygote) I and II. Anaphase was found to be normal showing equal separation (3-3) of chromosomes in the control plants, but in the translocation heterozygotes infrequent occurrence of anaphasic abnormalities were met with and the types of these anomalies were found to be identical in both of them (Figs. 7-11, Table 2).

TH I: Conspicuously high incidence of pollen sterility (50.4\% and 50.55\%) was recorded in this normal looking plant during 2 consecutive years, while the control plants showed only $1.12 \%$ to $3.91 \%$ sterile pollen (Table 2). A quadrivalent was found to be present in all the male meiocytes along with a bivalent at diakinesis and metaphase I in both the years of observations (Figs. 3, 4). Only in a few PMCs $(0.32 \%)$ the quadrivalent was come across with two univalents during the second year of observations (Fig. 5). Chain configuration of the quadrivalent was found to occur more frequently (78.60\% and $94.09 \%$ ) than ring configuration and alternate type of orientation of chromosomes was more common than adjacent type (Table 1). In all cases both chain and ring shaped quadrivalents were found to be in close association with nucleolus (Figs. 3, 4). Frequency of chiasma in this plant varied from 6.44 to 6.90 /cell and 2.14 to 2.30 /bivalent, while in the control plant the range of chiasma frequency was 8.35 to $8.87 /$ cell and 2.61 to $2.94 /$ bivalent during the 2 consecutive years (Table 1). In contrast to normal (3-3) anaphasic separation of chromosomes in the control plants, irregularities like unequal separation of chromosomes, anaphasic bridge, late separation of chromosomes, lagging chromosome and bridge with a laggard were encountered in this plant at anaphase I (Figs. 8-10, Table 2).

TH II: This plant was also morphologically indistinguishable from others, but exhibited considerably higher percentage of pollen sterility $(60.38 \%$ to $72.70 \%)$ than TH I (Table 2$)$. Analysis of its PMCs revealed presence of a quadrivalent in most of the microsporocytes $(76.40 \%)$ in the first year and in all the PMCs observed (100.00\%) during the the second year (Figs. 6, 7, Table 1). Oc- 
currence of 3 bivalents was noticed in a rather few cases only. Ring shaped quadrivalent was found to be present in remarkably high number of PMCs $(84.89 \%$ and $94.52 \%)$ than chain type during both the years. The quadrivalent, in no case, was found to be adhered to nucleolus (Figs. 6, 7). The range of chiasma frequency varied from 5.97 to 6.61 /cell and 1.99 to 2.20 /bivalent during the 2 years (Table 1). On an average, adjacent type of orientation was more frequent than alternate type. Similar type of anaphasic anomalies were found to occur as observed in TH I (Figs. 11, Table 2).

\section{Discussion}

The 2 phenotypically normal looking semisterile plants detected in the post-irradiated plant progeny of Ornithogalum virens L. raised through gamma-ray irradiation were characterized cytogenetically by high incidence of pollen sterility preceded with very high frequency of meiotic anomalies as compared to control materials. In contrast to normal bivalent pairing association in the control plants regular presence of a quadrivalent in both the semisterile plants provided them with the characteristics of translocation heterozygotes. The quadrivalent in the post-irradiated plants might have appeared as a consequence of induced breakages followed by reciprocal translocation between 2 non-homologous pairs of chromosomes. Close association of the quadrivalent with nucleolus in all the male meiocytes was the unique feature in TH I, and this has indicated involvement of a pair of satellited chromosomes in reciprocal translocation. Non-adherence of the quadrivalent with nucleolus, on the contrary, rules out the possibility of translocation in the chromosomes bearing secondary constrictions in TH II. Involvement of a nucleolar-organising chromosome pair in quadrivalent formation through reciprocal translocation has been reported in maize (Burnham 1962) and gamma-ray irradiated plants of grass pea (Biswas and Biswas 1997). Chain shaped quadrivalent appeared more frequently in TH I, while ring type occurred predominantly in TH II. A ring of 4 may arise through subterminal or terminal chiasma formation, the shape of which may be modified in to a figure of 8 due to presence of an interstitial and 2 terminal chiasmata. Absence of any chiasma in a particular arm, or by opening out of the chiasma formed in the concerned arm may give rise to a chain quadrivalent. Reciprocal translocation between 2 relatively large-sized chromosomes close to centromere forming more or less equal sized interchanged segments has been ascribed for ring configuration of quadrivalent (Burnham 1962). In the present material the interchanged chromosome segment being long enough for chiasma formation may facilitate origin of a ring quadrivalent. Conversely, higher frequency of chain type quadrivalent has been attributed to small sized chromosomes in Brassica (Kumar and Das 1973).

In both the translocation heterozygotes semisterility of pollen may be attributed to very high incidence of quadrivalent association and adjacent orientation in considerably high number of PMCs. Universal presence of a quadrivalent has been ascribed for semisterility in X-irradiated progeny of a pure line rice variety P-24 and in Pennisetum typhoides (Chandrasekharan et al. 1975). Semisterility in pollen or ovules is a consequence of heterozygous translocation; in barley it was shown to result from irregularities in segregation of heterozygous translocations that developed as deficiencies and duplications (Gardner and Snustad 1984). Usually in translocation heterozygote, crossing over in an interstitial segment followed by adjacent segregation results in sterility in 50\% of the gametes, while viable gametes are produced through alternate disjunction (Singh 2003). Pollen sterility in TH II increased to a greater extent possibly due to predominance of ring quadrivalent and adjacent orientation. Fertility, on the contrary, was assumed to be restored by higher frequency of chain quadrivalent and alternate disjunction in case of TH I. It appeared that anaphasic anomalies being identical and infrequent played rather insignificant role in distinguishing the 2 translocation heterozygotes. 


\section{Acknowledgement}

The authors expressed their gratefulness to Late Prof. S. Dana, Bidhan Chandra Krishi Vishwavidyalaya, West Bengal, India for supplying the irradiated seed materials.

\section{References}

Biswas, S. C. and Biswas, A. K. 1997. Induced translocation heterozygosity and sterility in Lathyrus sativus L. Bangladesh J. Bot. 26: 131-136.

Burnham, C. R. 1962. Discussion in Cytogenetics. Burgess Publ. Co., Minnesota, U.S.A.

Chandrasekharan, S. N., Parthasarathy, S. V., Krishnaswamy, N., Hrishi, N. 1975. Cytogenetics and Plant Breeding. P. Varadachary \& Co., Madras, pp. 141.

Gardner, E. J. and Snustad D. P. 1984. Principles of Genetics, John Wiley \& Sons, New York., pp. 445.

Jauhar, P. P. and Storey, W. B. 1982. Ornithogalum virens: a useful organism for teaching cytology. J. Hered. 73: 243-244.

Kumar, P. R. and Das, K. 1973. Radiation induced chromosomal interchanges in Brassica campestris. Cytologia 38: 587-592.

Singh, B. D. 2003. Genetics. Kalyani Publishers, Ludhiana, New Delhi, pp. 119. 